\title{
A simplified green chemistry approaches to organic synthesis in solid media. Activated fly ash, an industrial waste (pollutant) as an efficient and novel catalyst for some selected organic reactions in solvent-free conditions under microwave irradiation
}

\author{
M. Gopalakrishnan, ${ }^{*}$ P. Sureshkumar, V. Kanagarajan, J. Thanusu, and \\ R. Govindaraju \\ * Department of Chemistry, Annamalai University, Annamalai Nagar-608 002, India \\ E-mail:
}

\begin{abstract}
Activated Fly ash, an industrial waste (pollutant) is found to be well suited for catalyzing reactions which are having industrial, pharmacological and therapeutic importance, e.g. Knoevenagel condensation, 'One-Pot' conversions of ketones to amides, via, Beckmann rearrangement, Schiff Bases formation, Biginelli and Hantzsch reactions under microwave irradiation in solvent-free conditions. Moreover, this catalyst shows a promising future in that it can provide environmentally clean processes for the chemical industry.
\end{abstract}

Keywords: Activated Fly ash, Knoevenagel condensation, Beckmann rearrangement, Schiff Bases formation, Biginelli and Hantzsch reactions

\section{Introduction}

Microwave irradiation (MWI) has become an established tool in organic synthesis, because of the rate enhancements, higher yields, and often, improved selectivity, with respect to the conventional reaction conditions. ${ }^{1}$ In recent years, solvent -free reactions using either organic or inorganic solid supports have received increasing attention. ${ }^{2}$ There are several advantages to performing synthesis in dry media: (i) short reaction times, (ii) increased safety, (iii) economic advantages due to the absence of solvent. In addition, solvent free MWI processes are also clean and efficient.

Owing to environmental restrictions on emissions covered in several legislations throughout the world, non-polluting and atom-efficient catalytic technologies are much sought after. The use of acid catalysts is very common in the chemical and refinery industries, and those technologies employing highly corrosive, hazardous and polluting liquid acids are being replaced with solid acids; for instance, acid treated clays, zeolites, zeotypes, ion-exchange 
resins and metal oxides. Of late, a number of organic syntheses have been conducted with solid acids like sulfated zirconia ${ }^{3}$ leading to better regio- and stereo- selectivity.

The challenge in chemistry to develop practical processes, reaction media, conditions and/or utility of materials based on the idea of green chemistry is one of the important issues in the scientific community. ${ }^{4}$ Owing to our interest in solid-state reactions, ${ }^{5}$ we attempted to use Activated Fly ash to catalyze reactions which have industrial, pharmacological and therapeutic importance.

There has been about 70 years of research and use of Fly ash. With its application, the action mechanism of Fly ash had been recognized. During the initial stage, only its pozzolanic activity was paid attention. ${ }^{6,7}$ Many researchers devoted themselves to the research of the potential activity of Fly ash and the hydration process of Fly ash cement. ${ }^{8}$ The objective of the present investigation is to activate the as-received Fly ash by a physical method followed by a thermal method and to study the influence of Activated Fly ash to catalyze reactions such as Knoevenagel condensation," 'One-Pot' conversions of ketones to amides via, Beckmann rearrangement ${ }^{10}$, Schiff Bases formation ${ }^{11}$, Biginelli $^{12}$ and Hantzsch $^{13}$ reactions (Scheme 1).

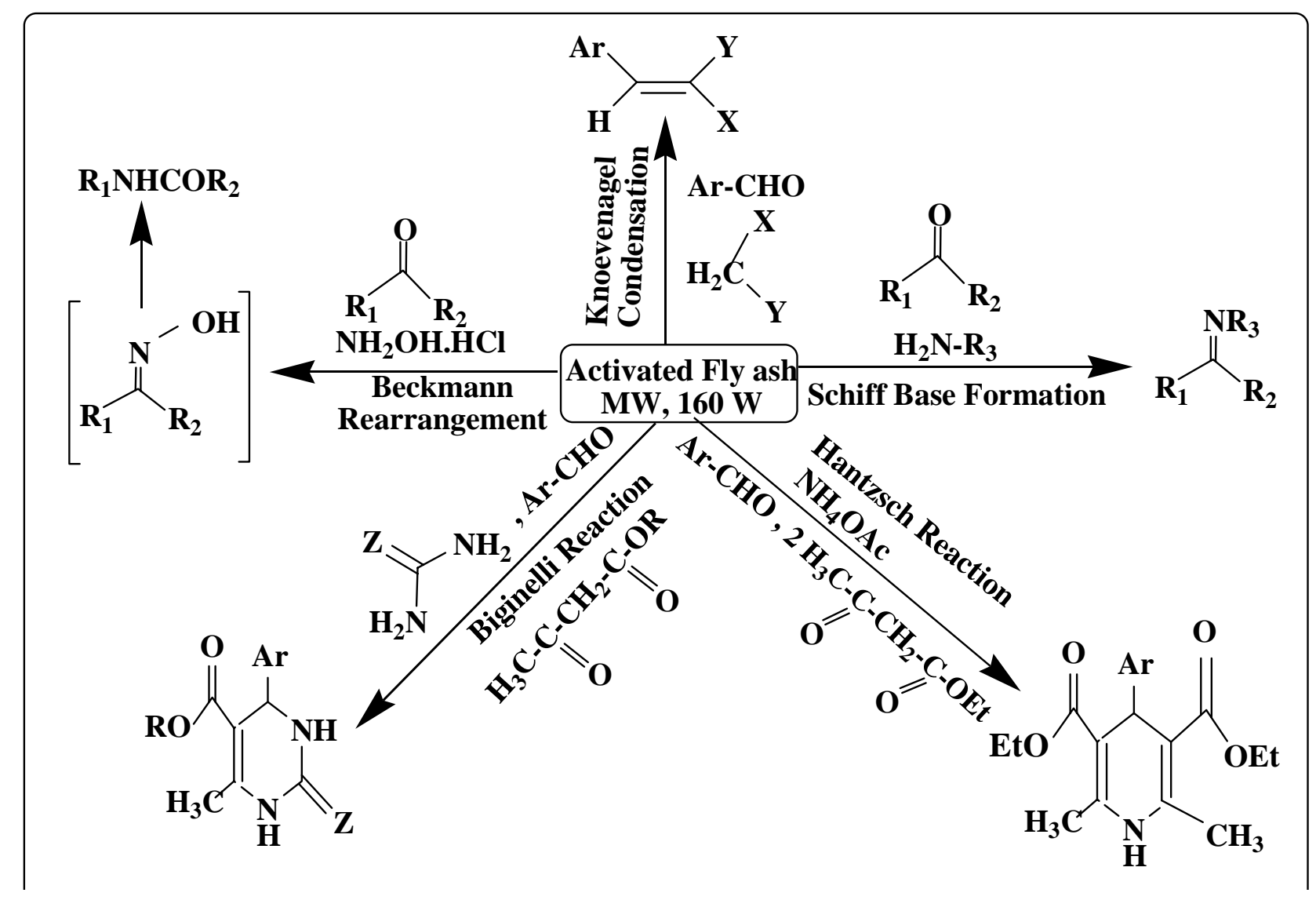

Scheme 1. Solvent-free microwave assisted fly ash catalyzed reactions 


\section{Results and Discussion}

\section{Fly ash used}

The Fly ash collected from Neyveli Lignite Corporation, Neyveli, Tamil Nadu, India was utilized for catalyzing the reactions. The physical properties, such as specific gravity and specific surface area, of Fly ash used were 1.9 and $127 \mathrm{~m}^{2} / \mathrm{g}$, respectively. The chemical compositions of Fly ash $^{8 \mathrm{a}}$ used are reported in Table 1.

Table 1. Composition of fly ash used in this study

\begin{tabular}{|c|c|}
\hline Constituents & Fly ash (\%) \\
\hline $\mathrm{SiO}_{2}$ & 64.03 \\
\hline $\mathrm{Fe}_{2} \mathrm{O}_{3}$ & 6.50 \\
\hline $\mathrm{Al}_{2} \mathrm{O}_{3}$ & 15.50 \\
\hline $\mathrm{CaO}$ & 4.62 \\
\hline $\mathrm{MgO}$ & 3.00 \\
\hline Loss on ignition & 4.35 \\
\hline Insoluble residue & 2.00 \\
\hline
\end{tabular}

\section{Activated Fly ash was prepared as follows}

The Fly ash as-received was sieved in a 100 mesh sieve to remove any coarser and foreign particles and then mechanically ground in a ball mill to fine powder. The particle size distribution was found to be between 40 and $90 \mu \mathrm{m}$. Finely ground Fly ash was kept at a temperature of about $900-1000^{\circ} \mathrm{C}$ in a silica crucible for $1 \mathrm{~h}$ for activation and was used for investigation (Figure 1). The carbon, sulphur and other impurities were removed by thermal activation and the resultant Fly ash is called Activated Fly ash.

Activated Fly ash was shown to be one of the most efficient MW absorbers with a very high specificity to MW heating. It was able to reach a temperature of $135^{\circ} \mathrm{C}$ after 6 minutes of irradiation in domestic oven. $(\mathrm{P}=320 \mathrm{~W})$. 


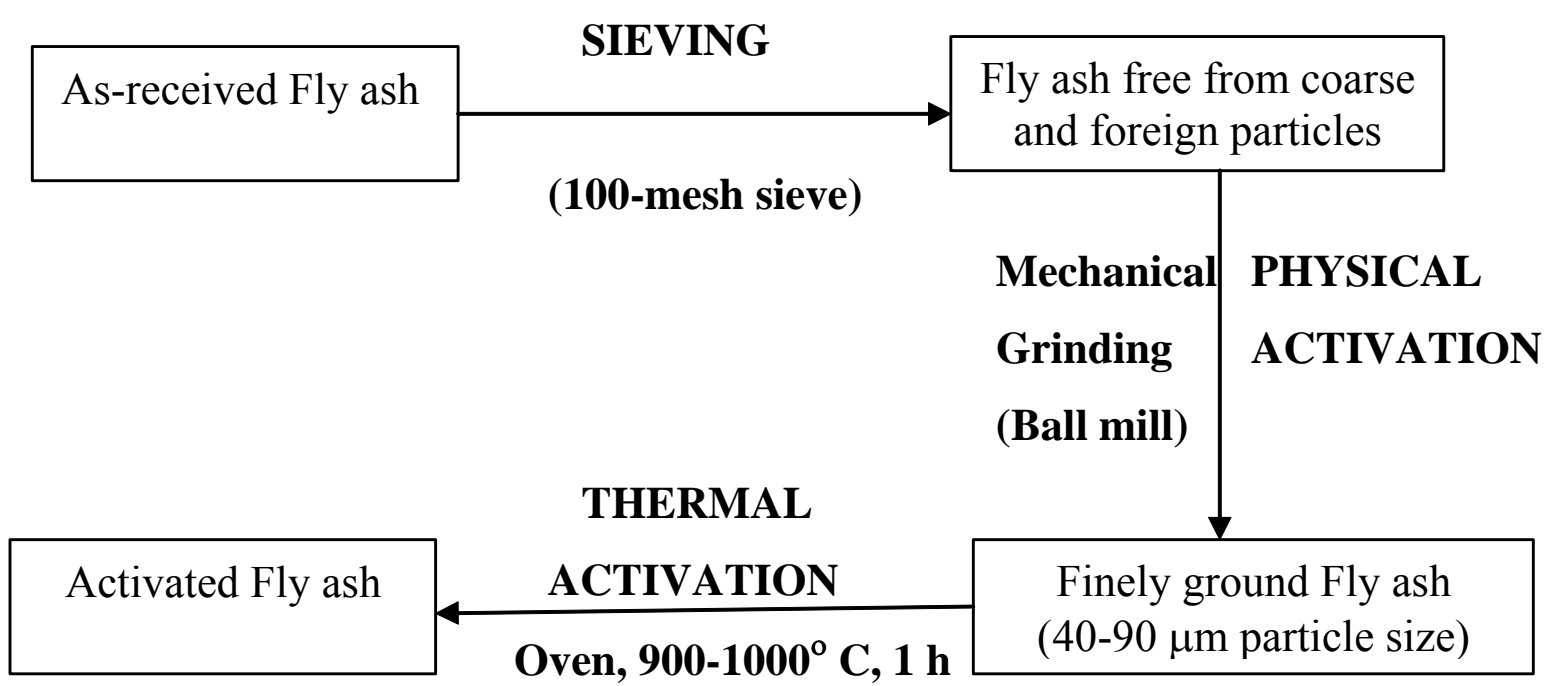

Figure 1. Flow-chart for the preparation of Activated Fly ash

\section{Stereoselective Knoevenagel condensation}

A wide range of substrates including electron-rich and electron-deficient aromatic aldehydes, heterocyclic aldehydes like furfural, thiophene-2-carboxaldehyde on condensation with active methylene compounds namely malonic acid, malononitrile and ethyl cyanoacetate provided $\alpha, \beta$-unsaturated acids, $\alpha$-cyanoacrylonitriles and $\alpha$-cyanoacrylates respectively in solvent-free conditions under MW irradiation catalyzed by Activated Fly ash.

In this study, Activated Fly ash has been employed as a novel, mild and efficient catalyst for this condensation. The presence of $\mathrm{SiO}_{2}$ and $\mathrm{Al}_{2} \mathrm{O}_{3}{ }^{9 \mathrm{~b}}$ in Activated Fly ash induces the reaction. In all the cases, the reaction proceeds smoothly with 2:1 ratio of Activated Fly ash to substrates, following the reaction conditions mentioned in Table 2. The reaction is highly stereo selective, affording, $\alpha, \beta$ - ethylenic compounds in excellent yields, with an $E$ geometry. In addition, the use of Activated Fly ash as a catalyst helps to avoid the use of environmentally unfavorable organic solvents as reaction medium since the reaction proceeds smoothly under solvent-free conditions. ${ }^{9 \mathrm{c}}$

\section{'One-Pot' conversions of ketones to amides, via, Beckmann rearrangement}

Treatment of ketones with hydroxylamine hydrochloride in the presence of Activated Fly ash afford the corresponding amides in 'One-Pot' in high yields (Table 3) in dry media under microwave irradiation without any of the environmental disadvantages of using toxic reagents such as sodium azide, nitro paraffin and sulfuric acid. The mechanism of the conversion could briefly be proposed as follows: the ketones at first reacted with hydroxylamine to produce ketoximes which then underwent Beckmann rearrangement to afford the amides. The presence of $\mathrm{CaO}^{10 \mathrm{c}}$ in Activated Fly ash triggers the reaction to form intermediate ketoximes. The presence of $\mathrm{SiO}_{2}$ and $\mathrm{Al}_{2} \mathrm{O}_{3}{ }^{10-\mathrm{d} \text {,e }}$ in Activated Fly ash further drives the reaction to form 
amides by Beckmann rearrangement. The major products were formed by migration of the aryl group of the intermediate ketoximes during rearrangement. Moreover, the present method was found to be suited for the preparation of valerolactam and $\varepsilon$-caprolactam, an essential intermediate for Nylon-6 manufacture ${ }^{10 a}$.

Table 2. Activated Fly ash catalyzed facile synthesis of aromatic $\alpha, \beta$-unsaturated acids and aromatic/heterocyclic $\alpha$-cyanoacrylonitriles, $\alpha$-cyanoacrylates via, a Knoevenagel reaction

\begin{tabular}{|c|c|c|c|c|c|c|c|}
\hline \multirow[b]{2}{*}{ Entry } & \multirow[b]{2}{*}{$\mathrm{Ar}$} & \multirow[b]{2}{*}{$\mathrm{X}$} & \multirow[b]{2}{*}{$\mathrm{Y}$} & \multicolumn{2}{|c|}{ Reaction conditions } & \multirow{2}{*}{$\begin{array}{c}\text { Isolated } \\
\text { yields }^{\mathrm{b}, \mathrm{d}} \\
(\%)\end{array}$} & \multirow{2}{*}{$\begin{array}{c}\text { m.p. }\left({ }^{\circ} \mathrm{C}\right) \\
\text { Found / } \\
\text { Reported }\end{array}$} \\
\hline & & & & $\begin{array}{c}\text { Temperature } \\
\quad, \mathrm{b}\left({ }^{\circ} \mathrm{C}\right)\end{array}$ & $\begin{array}{c}\text { Time }^{\mathrm{b}, \mathrm{c}} \\
(\mathrm{s})\end{array}$ & & \\
\hline 1 & $\mathrm{C}_{6} \mathrm{H}_{5}$ & $\mathrm{COOH}$ & $\mathrm{COOH}$ & $60-62(60)$ & $90(300)$ & $98(92)$ & $131-32 / 133$ \\
\hline 2 & $4-\mathrm{CH}_{3} \mathrm{OC}_{6} \mathrm{H}_{4-}$ & $\mathrm{COOH}$ & $\mathrm{COOH}$ & $64-66(65)$ & $\begin{array}{c}110 \\
(420) \\
\end{array}$ & $89(82)$ & $168-69 / 170$ \\
\hline 3 & $3-\mathrm{NO}_{2} \mathrm{C}_{6} \mathrm{H}_{4}-$ & $\mathrm{COOH}$ & $\mathrm{COOH}$ & $67-69(70)$ & $\begin{array}{c}140 \\
(600)\end{array}$ & $83(74)$ & $198 / 200-01$ \\
\hline 4 & $4-\mathrm{CH}_{3} \mathrm{C}_{6} \mathrm{H}_{4-}$ & $\mathrm{CN}$ & $\mathrm{CN}$ & $64-66(65)$ & $\begin{array}{c}130 \\
(480)\end{array}$ & $95(86)$ & $\begin{array}{c}125-26 / 128- \\
30\end{array}$ \\
\hline 5 & $4-\mathrm{ClC}_{6} \mathrm{H}_{4-}$ & $\mathrm{CN}$ & $\mathrm{CN}$ & $62-64(60)$ & $\begin{array}{c}130 \\
(420)\end{array}$ & $91(83)$ & $160 / 161$ \\
\hline 6 & Furfural & $\mathrm{CN}$ & $\mathrm{CN}$ & $58-60(60)$ & $\begin{array}{c}110 \\
(360) \\
\end{array}$ & $87(80)$ & $71-72 / 72$ \\
\hline 7 & $\begin{array}{l}\text { Thiopene-2- } \\
\text { carboxaldehyde }\end{array}$ & $\mathrm{CN}$ & $\mathrm{CN}$ & $54-56(55)$ & $\begin{array}{c}100 \\
(300)\end{array}$ & $90(81)$ & $90-91 / 92$ \\
\hline 8 & $\mathrm{C}_{6} \mathrm{H}_{5^{-}}$ & $\mathrm{CN}$ & COOEt & $58-60(60)$ & $\begin{array}{c}110 \\
(360)\end{array}$ & $95(83)$ & $47-48 / 49$ \\
\hline 9 & $4-\mathrm{CH}_{3} \mathrm{OC}_{6} \mathrm{H}_{4-}$ & $\mathrm{CN}$ & COOEt & $64-66(65)$ & $\begin{array}{c}120 \\
(420)\end{array}$ & $96(84)$ & $88 / 90$ \\
\hline 10 & $4-\mathrm{NO}_{2} \mathrm{C}_{6} \mathrm{H}_{4-}$ & $\mathrm{CN}$ & COOEt & $68-70(70)$ & $\begin{array}{c}130 \\
(420)\end{array}$ & $95(80)$ & $165-66 / 168$ \\
\hline 11 & Furfural & $\mathrm{CN}$ & COOEt & $60-62(60)$ & $\begin{array}{c}140 \\
(660)\end{array}$ & $89(79)$ & $92 / 93$ \\
\hline 12 & $\begin{array}{l}\text { Thiopene-2- } \\
\text { carboxaldehyde }\end{array}$ & $\mathrm{CN}$ & COOEt & $56-58(55)$ & $\begin{array}{c}120 \\
(480)\end{array}$ & $92(80)$ & $105-106 / 108$ \\
\hline
\end{tabular}

${ }^{\mathrm{a}}$ The reaction temperature was measured by immersing a glass thermometer in the reaction mixture at the end of the exposure to microwave irradiation and gives an approximate temperature range.

${ }^{\mathrm{b}}$ The data in parenthesis refer to the reaction conditions under thermal conditions.

${ }^{\mathrm{c}}$ Time at which maximum yield was obtained.

${ }^{\mathrm{d}}$ Isolated yields of pure products. 


\section{Formation of Schiff bases}

During the course of our studies aimed at developing solvent-free procedures, we found that the use of Activated Fly ash catalyzed nucleophilic attack on the carbonyl group by the amine and served as a dehydrating agent to facilitate the removal of water in the final step both under microwave and thermal conditions.

Table 3. 'One-Pot' conversion of ketones into amides with Activated Fly ash, via, Beckmann rearrangement

\begin{tabular}{|c|c|c|c|c|c|c|}
\hline \multirow{2}{*}{ Entry } & \multicolumn{2}{|c|}{ Ketone / amide } & \multirow{2}{*}{$\begin{array}{c}\text { Reaction } \\
\text { Temp. }{ }^{\mathrm{a}, \mathrm{b}} \\
\left({ }^{\circ} \mathrm{C}\right)\end{array}$} & \multirow{2}{*}{$\begin{array}{l}\text { Time }^{\mathrm{b}} \\
(\mathrm{s})\end{array}$} & \multicolumn{2}{|c|}{$\begin{array}{l}\text { Isolated yields } \\
(\%) \text { of amide }\end{array}$} \\
\hline & $\mathrm{R}_{1}$ & $\mathrm{R}_{2}$ & & & \multicolumn{2}{|c|}{$\begin{array}{c}\mathrm{MW}^{\mathrm{c}} / \text { Conventional } \\
\text { heating }\end{array}$} \\
\hline 1 & $\mathrm{Ph}$ & $\mathrm{Me}$ & $58-60(60)$ & $120(420)$ & 92 & 84 \\
\hline 2 & Naphth-2-yl & $\mathrm{Me}$ & $57-58(60)$ & $140(480)$ & 90 & 78 \\
\hline 3 & $4-\mathrm{MeOC}_{6} \mathrm{H}_{4-}$ & $\mathrm{Me}$ & $60-62(60)$ & $150(600)$ & 93 & 81 \\
\hline 4 & $4-\mathrm{ClC}_{6} \mathrm{H}_{4}-$ & $\mathrm{Me}$ & $54-56(55)$ & $160(660)$ & 88 & 77 \\
\hline 5 & $\mathrm{Me}$ & Et & $44-46(45)$ & $180(540)$ & 75 & 63 \\
\hline 6 & $-\left(\mathrm{CH}_{2}\right)_{4}^{-}$ & & $48-50(50)$ & $180(660)$ & 90 & 78 \\
\hline 7 & $-\left(\mathrm{CH}_{2}\right)_{5^{-}}$ & & $47-49(50)$ & $150(480)$ & 93 & 75 \\
\hline 8 & $\mathrm{Ph}$ & Et & $58-60(60)$ & $140(540)$ & 91 & 79 \\
\hline 9 & $\mathrm{Ph}$ & $\mathrm{Ph}$ & $59-60(60)$ & $180(660)$ & 94 & 80 \\
\hline
\end{tabular}

${ }^{a}$ Reaction temperature was measured by immersing a glass thermometer into the reaction mixture immediately after exposure to microwave irradiation.

${ }^{\mathrm{b}}$ The data in parenthesis refer to the reaction conditions under conventional heating. ${ }^{\mathrm{c}} \mathrm{MW}=$ Microwave irradiation

Activated Fly ash catalyzes the reactions of structurally diverse carbonyl compounds and various amines under mild conditions to give the corresponding Schiff bases ${ }^{11}$ in excellent yields (Table 4). The scope and limitations of Activated Fly ash as a catalyst for Schiff base formation is established by condensing 3,4-dimethoxybenzaldehyde with 4nitroaniline, since the presence of the methoxy group in the carbonyl compound reduces the electrophilicity of the carbonyl compound through resonance and the strong electron withdrawing property of the nitro group in the amine decreases the nucleophilicity of the amine group. $\mathrm{SiO}_{2}$ and $\mathrm{Al}_{2} \mathrm{O}_{3}$, the key constituent in Activated Fly ash induces the reaction. 
Table 4. Microwave assisted formation of Schiff bases catalyzed by Activated Fly ash

\begin{tabular}{|c|c|c|c|c|c|}
\hline Entry & Substrate & Amine & $\begin{array}{l}\text { Reaction } \\
\text { temp. }{ }^{\mathrm{a}, \mathrm{b}} \\
\left({ }^{\circ} \mathrm{C}\right)\end{array}$ & $\begin{array}{c}\text { Time }^{\mathrm{b}} \\
(\mathrm{s})\end{array}$ & $\begin{array}{l}\text { Isolated } \\
\text { yields }^{\text {b }} \\
(\%)\end{array}$ \\
\hline 1 & & & $58-60(55)$ & $90(280)$ & $96(83)$ \\
\hline 2 & & & $60-62(65)$ & $110(360)$ & $93(81)$ \\
\hline 3 & & & $58-60(60)$ & $100(300)$ & $95(79)$ \\
\hline 4 & & & $62-64(65)$ & $120(720)$ & $91(80)$ \\
\hline 5 & & & $63-65(60)$ & $130(540)$ & $95(81)$ \\
\hline 6 & & & $68-70(70)$ & $120(660)$ & $98(84)$ \\
\hline 7 & & & $46-48(45)$ & $180(900)$ & $74(63)$ \\
\hline 8 & & & $54-56(55)$ & $160(720)$ & $79(66)$ \\
\hline 9 & & & $52-54(55)$ & $330(720)$ & $76(60)$ \\
\hline 10 & & & $58-60(60)$ & $360(900)$ & $82(74)$ \\
\hline
\end{tabular}

${ }^{\mathrm{a}}$ Final temperature was measured by immersing a glass thermometer in the reaction mixture at the end of the exposure to MW irradiation and gives an approximate temperature range. ${ }^{b}$ Yields of isolated products. 


\section{Modified Biginelli and Hantzsch reactions}

The multicomponent reactions (MCRs) are recently of practical importance due to their speed, diversity, and efficiency. Owing to our interest in solid-state reactions, we wish to report Activated Fly ash as an efficient catalyst for three component 'One-Pot' cyclocondensation reaction of $\beta$-dicarbonyl compounds and urea/thiourea with structurally diverse aromatic and heterocyclic aldehydes in solvent-free conditions to furnish the corresponding 3,4dihydropyrimidin- $2(1 \mathrm{H})$-ones and -thiones both under microwave irradiation and thermal conditions for the appropriate time as mentioned in Table 5, entries (1-9).

The positive results obtained from the Biginelli reactions prompted us to synthesize well-known pharmacologically important 1,4-dihydropyridines. The most prominent method for the synthesis of 1,4-dihydropyridines is the Hantzsch synthesis, which involves the cyclocondensation of two moles of ethyl acetoacetate with one mole of ammonium acetate and one mole of aldehydes in the presence of Activated Fly ash. Two major constituents of Activated Fly ash namely $\mathrm{SiO}_{2}$ and $\mathrm{Al}_{2} \mathrm{O}_{3}{ }^{12 \mathrm{~d}}$ trigger both Biginelli and Hantzsch reactions. Extending the modifications of the Biginelli reaction to Hantzsch synthesis gave excellent results (Table 5, entries 10, 11).

Experimental conditions have been carefully monitored to regulate the use of Activated Fly ash catalyst, the irradiation time and the power level of the microwave oven to get the maximum yield. The 2:1 ratio of Activated Fly ash catalyst to substrates is the most acceptable ratio in terms of efficiency, and a power level of $160 \mathrm{~W}$ is the most suitable one.

Finally in order to evaluate the possibility of specific non-thermal effects of microwave irradiation, reactions were carried out using a thermostated heating mantle $(\Delta)$ under similar sets of conditions of time and temperature as for the microwave-assisted method (Tables 2-5, parentheses data). Significant lower yields were obtained under conventional heating than when using the MW-assisted method under identical conditions of time and temperature. Even by extending reaction times, yields remain lower under thermal conditions when compared to MW activation. This observation clearly demonstrates that the effect of MW irradiation is not purely thermal.

\section{Conclusions}

The following broad conclusions can be drawn from the above results:

1) A facile synthesis of $\alpha, \beta$-unsaturated acids, $\alpha$-cyanoacrylonitriles and $\alpha$-cyanoacrylates has been achieved with an E- geometry via, a stereo selective Knoevenagel reaction by employing Activated Fly ash as catalyst.

2) A great variety of amides were effectively isolated from ketones in 'One-Pot' via, Beckmann rearrangement under mild conditions during the reactions lead to a clean, efficient, convenient and economical technology. 
3) Schiff base, a versatile intermediate in medical and organic chemistry has been synthesized efficiently by Activated Fly ash, thus rendering the process more economical.

4) Modified Biginelli and Hantzsch reactions were carried using environmentally benign processes.

The attractive features of this procedure are the mild reaction conditions, high conversions, cleaner reaction profiles, solvent-free reaction conditions, operational simplicity and inexpensive and readily available Fly ash, an industrial waste (pollutant), which act as a catalyst will make it a useful and attractive strategy for the preparation of industrial, pharmacological and therapeutic important compounds.

Table 5. An alternative methodology to the Biginelli and Hantzsch reactions using Activated Fly ash

\begin{tabular}{|c|c|c|c|c|c|c|c|}
\hline \multirow[b]{2}{*}{ Entry } & \multirow[b]{2}{*}{$\mathrm{Ar}$} & \multirow[b]{2}{*}{$\mathrm{R}$} & \multirow[b]{2}{*}{ Z } & \multicolumn{2}{|c|}{ Reaction conditions } & \multirow{2}{*}{$\begin{array}{c}\text { IsolatedYields }{ }^{\mathrm{b}} \\
(\%)\end{array}$} & \multirow{2}{*}{$\begin{array}{c}\text { Melting point } \\
\left({ }^{\circ} \mathrm{C}\right) \text { Found } / \\
\text { Reported }\end{array}$} \\
\hline & & & & $\begin{array}{c}\text { Temperature }{ }^{\mathrm{a}, \mathrm{b}} \\
\left({ }^{\circ} \mathrm{C}\right)\end{array}$ & $\begin{array}{c}\operatorname{Time}^{\mathrm{b}} \\
(\mathrm{s})\end{array}$ & & \\
\hline 1 & $\mathrm{C}_{6} \mathrm{H}_{5}$ & $\mathrm{C}_{2} \mathrm{H}_{5}$ & $\mathrm{O}$ & $65-66(65)$ & $\begin{array}{c}45 \\
(120)\end{array}$ & $99(85)$ & 201/202-04 \\
\hline 2 & $3-\mathrm{O}_{2} \mathrm{NC}_{6} \mathrm{H}_{4}$ & $\mathrm{C}_{2} \mathrm{H}_{5}$ & $\mathrm{O}$ & $68-70(65)$ & $\begin{array}{c}70 \\
(300)\end{array}$ & $92(80)$ & $225 / 227-29$ \\
\hline 3 & $4-\mathrm{FC}_{6} \mathrm{H}_{4}$ & $\mathrm{C}_{2} \mathrm{H}_{5}$ & $\mathrm{O}$ & $63-65(65)$ & $\begin{array}{c}50 \\
(180)\end{array}$ & $96(83)$ & $183-84 / 185-86$ \\
\hline 4 & $4-\mathrm{H}_{3} \mathrm{CC}_{6} \mathrm{H}_{4}$ & $\mathrm{C}_{2} \mathrm{H}_{5}$ & $\mathrm{O}$ & $58-60(60)$ & $\begin{array}{c}80 \\
(240)\end{array}$ & $95(81)$ & $170-71 / 172$ \\
\hline 5 & 2-Furyl & $\mathrm{C}_{2} \mathrm{H}_{5}$ & $\mathrm{O}$ & $57-59(55)$ & $\begin{array}{c}45 \\
(150)\end{array}$ & $92(83)$ & 202-03/204-05 \\
\hline 6 & $4-\mathrm{ClC}_{6} \mathrm{H}_{4}$ & $\mathrm{CH}_{3}$ & $\mathrm{O}$ & $65-67(65)$ & $\begin{array}{c}60 \\
(250)\end{array}$ & $92(78)$ & 203/204-05 \\
\hline 7 & $4-\mathrm{H}_{3} \mathrm{CC}_{6} \mathrm{H}_{4}$ & $\mathrm{CH}_{3}$ & $\mathrm{O}$ & $54-56(55)$ & $\begin{array}{c}70 \\
(360)\end{array}$ & $90(81)$ & $204 / 204$ \\
\hline
\end{tabular}




\begin{tabular}{|l|l|l|l|c|c|c|c|}
\hline 8 & $\begin{array}{l}4- \\
\mathrm{H}_{3} \mathrm{COC}_{6} \mathrm{H}_{4}\end{array}$ & $\mathrm{C}_{2} \mathrm{H}_{5}$ & $\mathrm{~S}$ & $67-69(65)$ & $\begin{array}{c}90 \\
(270)\end{array}$ & $89(78)$ & $154 / 153-55$ \\
\hline 9 & 2-Thienyl & $\mathrm{CH}_{3}$ & $\mathrm{~S}$ & $64-66(65)$ & $\begin{array}{c}60 \\
(150)\end{array}$ & $87(75)$ & $233-34 / 236$ \\
\hline 10 & $\mathrm{C}_{6} \mathrm{H}_{5}$ & $\mathrm{C}_{2} \mathrm{H}_{5}$ & - & $58-60(60)$ & $\begin{array}{c}50 \\
(180)\end{array}$ & $98(84)$ & $156-57 / 157-59$ \\
\hline 11 & 2-Furyl & $\mathrm{C}_{2} \mathrm{H}_{5}$ & - & $63-65(65)$ & $\begin{array}{c}70 \\
(240)\end{array}$ & $93(78)$ & $161-62 / 164-65$ \\
\hline
\end{tabular}

${ }^{a}$ Final temperature was measured by immersing a glass thermometer in the reaction mixture at the end of the exposure to microwave irradiation and gives an approximate temperature range. ${ }^{\mathrm{b}}$ The data in parenthesis refer to the reaction conditions under conventional heating.

\section{Experimental Section}

General Procedures. All the inorganic/organic reagents used were pure commercial products. TLC was performed to ascertain proof of the reactions and purity of products. For the microwave irradiation experiments described below a conventional (unmodified) household microwave oven equipped with a turntable was used (LG, MG-395 WA, $760 \mathrm{~W}$ ) and operating at $2450 \mathrm{MHz}$. IR spectra were recorded in NICOLET-AVATAR-360 FT-IR Spectrophotometer in $\mathrm{KBr}$ pellets. Chemical Ionization Mass spectra were recorded on a FINNIGAN MAT-8230 Mass spectrometer. ${ }^{1} \mathrm{H}$ NMR spectra were recorded on a BRUKER AMX-400 NMR spectrometer (400 MHz) in $\mathrm{CDCl}_{3} / 80 \% \mathrm{CDCl}_{3}+\mathrm{DMSO}_{6} d_{6}$ using TMS as internal standard.

The structures of the products were confirmed by ${ }^{1} \mathrm{H}$ NMR, MS, FT-IR spectra and comparison with authentic samples obtained commercially or prepared by reported methods.

\section{Typical experimental procedure}

In all the cases, appropriate substrate and Activated Fly ash in 1:2 ratios were mixed thoroughly with the help of a mortar and pestle and the reaction mixture was placed in an alumina bath inside a microwave oven and irradiated, following the reaction conditions mentioned in Tables 2-5. Then the reaction mixture was cooled and extracted with ethyl acetate $(2 \times 15 \mathrm{~mL})$. The catalyst Activated Fly ash was removed by filtration and the filtrate was concentrated and the residue was subjected to column chromatography over silica gel using P.E.-EtOAc (3:1) as eluent to afford the corresponding products in good to excellent yields. 


\section{References}

1. (a) Caddick, S. Tetrahedron 1995, 51, 10403. (b) Deshayes, S.; Liagre, M.; Loupy, A.; Luche, J.; Petit, A.; Tetrahedron 1999, 55, 10851. (c) Lidstrom, P.; Tierney, J.; Wathey, B.; Westman, J. Tetrahedron 2001, 57, 9225. (d) Kirschning, A.; Monenschein, H.; Wittenberg, R.; Angew. Chem. Int. Ed. 2001, 73, 193. (e) Varma, R.S. Pure Appl. Chem. 2001, 73, 193. (f) Loupy, A.; Microwaves in Organic Synthesis; Wiley-VCH: Weinheim, 2002.

2. Diddams, P.; Butters, M. In Solid Supports and Catalysts in Organic Synthesis; Smith, K.; Ed.; Ellis Harwood and PTR Prentice Hall: New York and London, 1992, Chapters 1, 3 and 5.

3. Yadav, D. G.; Nair, J. J. Microporous and Mesoporous Materials, 1999, 33, 1.

4. Tundo, P.; Anastas, P. T. Green Chemistry: Challenging Perspectives, Oxford Science: Oxford, 1999.

5. (a) Gopalakrishnan, M.; Sureshkumar, P.; Kanagarajan, V.; Thanusu, J.; Govindaraju, R. J. Chem. Res. 2005, 5, 299. (b) Gopalakrishnan, M.; Sureshkumar, P.; Kanagarajan, V.; Thanusu, J. Lett. Org. Chem. 2005, 2, 136. (c) Gopalakrishnan, M.; Sureshkumar, P.; Kanagarajan, V.; Thanusu, J. Catal. Communications 2005, 6, 753.

6. Watt, J. D.; Throne, D. J. J. Appl. Chem. 1965, 15, 595.

7. Throne, D. J.; Watt, J. D. J. Appl. Chem. 1966, 16, 33.

8. (a) Saraswathy, V.; Muralidharan, S.; Thangavel, K.; Srinivasan, S. Cement Concr. Res. 2003, 25, 673. (b) Yueming, F.; Suhong, Y.; Zhiyun, W.; Jingyu, Z. Cement Concr. Res. 1999, 29, 467. (c) Caijunshi, Cement Concr. Res. 1996, 26, 1351.

9. (a) Knoevenagel, E.; Ber. 1898, 31, 2585. (b) Lehnert, W. Tetrahedron Lett. 1970, 54, 4723. (c) Kim, J.; Kwon, P.; Kwon, T.; Chung, S.; Lee, J. Synth. Comm. 1996, 26, 535. (d) Wada, S.; Suzuki, H. Tetrahedron Lett. 2003, 44, 399. (e) Su, C.; Chen, Z-C.; Zheng, Q.G. Synthesis 2003, 555. (f) Sebti, S.; Smahi, A.; Solhy, A. Tetrahedron Lett. 2002, 43, 1813. (g) Harjani, J. R.; Nara, S. J.; Salunkhe, M. M. Tetrahedron Lett. 2002, 43, 1127. (h) Yadav, J. S.; Subbareddy, B. V.; Basak, A. K.; Visali, B.; Narsaiah, A. V.; Nagaiah, K. Eur. J. Org. Chem. 2004, 546.

10. (a) Olah, G. A.; Fung, A. P. Synthesis 1979, 537. (b) Gawly, R. E. Org. React. 1988, 35, 1. (c) Gopalakrishnan, M.; Sureshkumar, P.; Thanusu, J.; Kanagarajan, V.; Govindaraju, R. Turkish J. Chem. 2006, (Communicated). (d) Murakami, Y.; Saeki, Y.; Ito, K. Nippon Kagaku Kaishi 1978, 21. (e) Yashima, T.; Horie, S.; Saito, S.; Hara, N. Nippon Kagaku Kaishi 1977, 77. (f) Chandrasekar, S.; Gopalaiah, K. Tetrahedron Lett. 2004, 44, 7537.

11. (a) Schiff, H. Annals. 1864, 131, 118. (b) Billman, J. H.; Tai, K. M. J. Org. Chem. 1958, 23, 535. (c) Varma, R. S.; Dahiya, R.; Kumar, S. Tetrahedron Lett. 1997, 38, 2039. (d) 
Chakraborti, A. K.; Bhagat, S.; Rudrawar, S. Tetrahedron Lett. 2004, 45, 7641. (e) Andrade, Z.; Suarenz, Z. Synlett, 2004, 12, 2135.

12. (a) Biginelli, P. Gazz. Chim. Ital. 1893, 23, 360. (b) Shaabani, A.; Bazgir, A.; Teimouri, F. Tetrahedron Lett. 2003, 44, 857. (c) Paraskar, A. S.; Dewkar, G. K.; Sudalai, A. Tetrahedron Lett. 2003, 44, 3305. (d) Martinez, S.; Meseguer, M.; Casas, L.; Rodriguez, E.; Molins, E.; Moreno-Manas, M.; Roig, A.; Sabastian, R. M.; Vallribera, A. Tetrahedron 2003, 59, 1553. (e) Bose, A. K.; Pednekar, S.; Ganguly, S. N.; Chakraborty, G.; Manhas, M. S. 2004, 45, 8351.

13. (a) Hantzsch, A. Liebigs Ann. Chem. 1882, 1, 215. (b) Yadav, J. S.; Reddy, B. V. S.; Reddy, K. B. Synth. Commun. 2001, 31, 425. (c) Breitenbucher, J. G.; Figliozzi, G. Tetrahedron Lett. 2000, 4311. 